JURNAL ILMIAH ELEKTRONIKA DAN KOMPUTER, Vol.14, No.1, Juli 2021, pp. 59 - 70

p-ISSN : $1907-0012$ (print)

e-ISSN : 2714-5417 (online)

http://journal.stekom.ac.id/index.php/elkom

page 59

\title{
Sistem Informasi Penerimaan Peserta Didik Baru Online pada SMK Nasional Pati
}

\author{
Evanita $^{1}$, Maulana Wijayanto ${ }^{2}$ \\ ${ }^{1,2}$ Universitas Muria Kudus \\ Jl. Lkr. Utara, Kayuapu Kulon, Gondangmanis, Kec. Bae, Kabupaten Kudus, Jawa Tengah 59327 \\ email : evanita@umk.ac.id ${ }^{1}$, maulavijay69@gmail.com²
}

ARTICLE INFO

Article history:

Received 30 Mei 2020

Received in revised form 2 Juni 2020

Accepted 10 Juni 2020

Available online 12 Juni 2020
ABSTRACT

Fieldwork Practices were carried out at Pati National Vocational High School, from January 25, 2021 to February 20, 2021. In this Fieldwork Practice, the authors created an efficient application and management system for student data, especially for new students in a computerized manner. By using this web-based programming system, it can simplify data collection, automatic ranking based on National Exam scores, reduce paper usage, reduce cheating and are expected to overcome the obstacles experienced by both the committee for admission of new students and the parents of the students themselves. . This research produces a system that can handle the admission process of new students with the hope that it is more efficient and effective than the previous method.

Keywords: programming, computerized, web.

\section{Pendahuluan}

Mengikuti perkembangan teknologi sekarang yang semakin canggih sehingga dapat membatu dan meringankan pekerjaan manusia dalam berbagai hal. Sekarang internet juga sudah menjadi kebutuhan pokok setiap manusia untuk menjelajah informasi dunia melalui web. Website merupakan salah satu teknologi yang dapat membantu manusia untuk berbagi informasi secara cepat dan tidak dibatasi waktu dan tempat. Dalam bidang manajemen, komputer menyediakan berbagai fasilitas untuk meningkatkan kualitas pelayanan seperti website sekolah untuk sumber informasi antara sekolah dan masyarakat maupun sistem informasi berbasi web untuk menunjang administrasi data sekolah.

Sejauh ini proses penerimaan peserta didik baru di SMK Nasional Pati masih menggunakan sistem yang kurang memadai dalam proses pendataan penerimaan siswa maka dari itu perlu sebuah sistem yang mampu menangani proses penerimaan peserta didik baru secara lebih efektif dan efisien sehingga mampu mempermudah pendataan, perangkingan berdasarkan nilai UN secara otomatis, mengurangi penggunaan kertas, mengurangi kecurangan yang kerap muncul setiap musim penerimaan siswa baru dan diharapkan dapat 
mengatasi hambatan-hambatan yang dialami baik oleh panitia penerimaan siswa baru maupun siswa itu sendiri.

Maka dari itu diperlukan pengembangan sistem informasi penerimaan peserta didik baru yang lebih akurat dan efisien agar memudahkan pengguna serta dapat diperbarui setiap saat dan pengguna dapat memilih jenis informasi yang diinginkan. Penulis mempunyai keinginan untuk mengembangkan sistem informasi penerimaan peserta didik baru berbasis web, Sistem ini didasarkan keinginan penulis untuk dapat menyediakan informasi tentang penerimaan peserta didik baru di SMK Nasional Pati agar dapat lebih mudah diakses dan digunakan oleh pengguna dan meningkatkan citra sekolah tersebut.

\section{Tinjauan Pustaka}

\subsection{Teori Penunjang}

Selama pelaksanaan Praktik Kerja Lapangan di SMK Nasional Pati, peserta

Praktik Kerja Lapangan menggunakan pengetahuan yang diperoleh selama masa perkuliahan sebagai landasan teori pembuatan Sistem Informasi Pada SMK Nasional

Pati. Pengetahuan dan teori yang digunakan antara lain:

1. Pengertian Sekolah Menengah Kejuruan

Sekolah Menengah Kejuruan (SMK) adalah salah satu bentuk satuan pendidikan formal yang menyelenggarakan pendidikan kejuruan pada jenjang pendidikan menengah sebagai lanjutan dari SMP/MTs atau bentuk lain yang sederajat atau lanjutan dari hasil belajar yang diakui sama/setara SMP/Mts[5].

2. Pengertian PPDB

PPDB merupakan proses pendaftaran siswa baru yang menggunakan sistem khusus dengan rancangan satu sumber atau pusat informasi sebagai server atau pengelola seleksi penerimaan siswa baru[3].

3. Konsep Pemrograman PHP

PHP adalah bahasa pemrograman yang sering disisipkan ke dalam HTML. PHP sendiri berasal dari kata Hypertext Preprocessor. Sejarah PHP pada awalnya merupakan kependekan dari Personal Home Page (Situs personal). PHP pertama kali dibuat oleh Rasmus Lerdorf pada tahun 1995. Pada waktu itu PHP masih bernama Form Interpreted (FI), yang wujudnya berupa sekumpulan skrip yang digunakan untuk mengolah data formulir dari web.

Bahasa pemrograman ini menggunakan sistem server-side. Server-side programming adalah jenis bahasa pemrograman yang nantinya script/program tersebut akan dijalankan/diproses oleh server. Kelebihannya adalah mudah digunakan, sederhana, dan mudah untuk dimengerti dan dipelajari.

4. Konsep Relational Database Management System (RDBMS)

Sebuah program komputer (atau secara lebih tipikal adalah seperangkat program komputer) yang didesain untuk mengatur/memanajemen sebuah basisdata sebagai sekumpulan data yang disimpan secara terstruktur, dan melakukan operasioperasi atas data atas permintaan penggunanya.

5. Konsep Analisa Sistem

Analisis sistem adalah tahapan penelitian terhadap sistem berjalan dan bertujuan untuk mengetahui segala permasalahan yang terjadi serta memudahkan dalam menjalankan tahap selanjutnya yaitu tahap perancangan sistem".

\subsection{Tools}

1) Sistem Operasi Linux

Penggunaan system operasi 1 sebagai pengatur semua proses yang terjadi di computer/CPU serta sebagai platform untuk menjalankan suatu software aplikasi.

JURNAL ILMIAH ELEKTRONIKA DAN KOMPUTER Vol. 14, No. 1, Juli 2021 : 59 - 70 
2) Visual Studio Code

Visual Studio Code (VS Code) adalah sebuah teks editor multiplatform yang komplit dan handal buatan Microsoft. Selain tersedia untuk Windows, Visual Studio Code (VS Code) juga tersedia untuk versi Linux dan Mac. Teks editor mendukung banyak bahasa pemrograman seperti JavaScript, Typescript, dan Node.js.

3) Xampp versi 3.2.4

$X A M P P$ merupakan sebuah perangkat lunak atau software yang bebas (open source) yang dapat digunakan di berbagai sistem operasi. XAMPP merupakan kompilasi dari beberapa program. XAMPP juga merupakan software web server Apache dan juga terdapat MySQL untuk penyimpanan database suatu aplikasi.lunak sistem manajemen basis data SQL..

4) My SQL Database

Sebuah perangkat lunak sistem manajemen basis data SQL. SQL (Structured Query Languange) adalah sekumpulan perintah khusus yang digunakan untuk mengakses data dalam database relational. Umumnya, setiap software-software RDBMS menyediakan 4 perintah DML dari SQL DML (Data Manipulation Languange) adalah perintah yang digunakan untuk mengoperasikan atau memanipulasi isi database.

5) Bootstrap

Bootstrap adalah sebuah library framework CSS yang dibuat khusus untuk bagian pengembangan front-end website. Bootstrap merupakan salah satu framework HTML, CSS dan Javascript yang paling popular di kalangan web develope, pada saat ini hampir semua web developer telah menggunakan bootstrap untuk membuat tampilan front-end menjadi lebih mudah dan sangat cepat, karena hanya perlu menambahkan class-class tertentu untuk misalnya membuat tombol, grid, navigasi, dan lainnya.Bootstrap telah menyediakan kumpulan komponen class interface dasar yang telah dirancang sedemikian rupa untuk menciptakan tampilan yang menarik, bersih, dan ringan. Selain komponen class interface, bootstrap juga memiliki fitur grid yang berfungsi untuk mengatur layout pada halaman website yang bisa digunakan dengan sangat mudah dan cepat. Dengan menggunakan bootstrap kita juga di beri keleluasaan dalam mengembangkan tampilan website yang menggunakan bootstrap yaitu dengan cara mengubah tampilan bootstrap dengan menambahkan class dan CSS sendiri.

6) Web Dinamis

Web Dinamis adalah web yang isinya selalu berubah-ubah atau berganti tiap waktu.Misalnya Blog, Toko Online, dan sebagainya.Sebuah web dinamis dirancang dengan menggunakan berbagai bahasa pemrograman web, baik itu jenis Client-side Script ataupun Server-Side Script. Bahasa pemrograman dari sisi server yang paling sering digunakan adalah PHP (Hypertext Preprocessor) yang fungsinya adalah untuk menginput, mengedit, mengambil dan mengolah data dari database untuk ditampilkan di 
halaman websitenya. Sedangkan bahasa pemrograman dari sisi clientnya adalah HTML dan Javascript.

\section{Hasil dan Pembahasan}

\subsection{Perancangan Sistem}

Dalam pembuatan aplikasi ini di perlukan perancangan sistem yang terdiri dari Flowchart, ERD, DFD, dan Tabel pada database. Agar memudahkan pada waktu merancang atau membuat sistem suatu aplikasi. Karena setiap analisa akan menghasilkan hasil yang bervariasi antara satu dan lainnya. Berikut adalah flowchart PPDB Online SMK Nasional Pati :

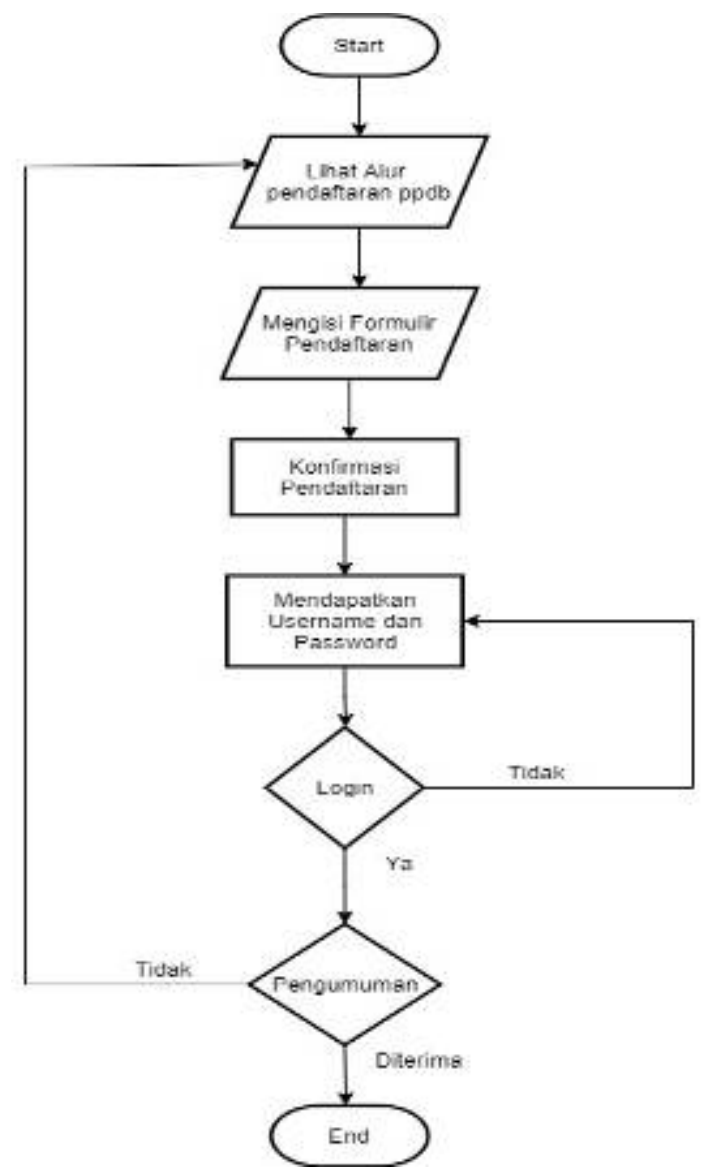

Gambar 1: Flowchart Calon Siswa 


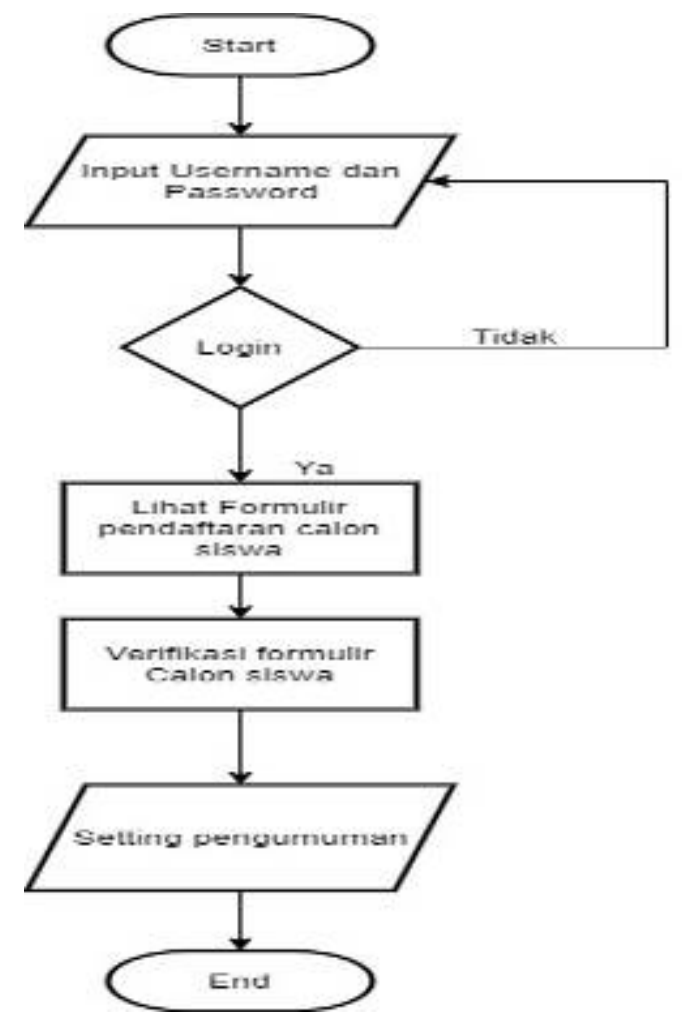

Gambar 2: Flowchart Admin

Berikut ERD Sistem Informasi PPDB SMK Nasional Pati :

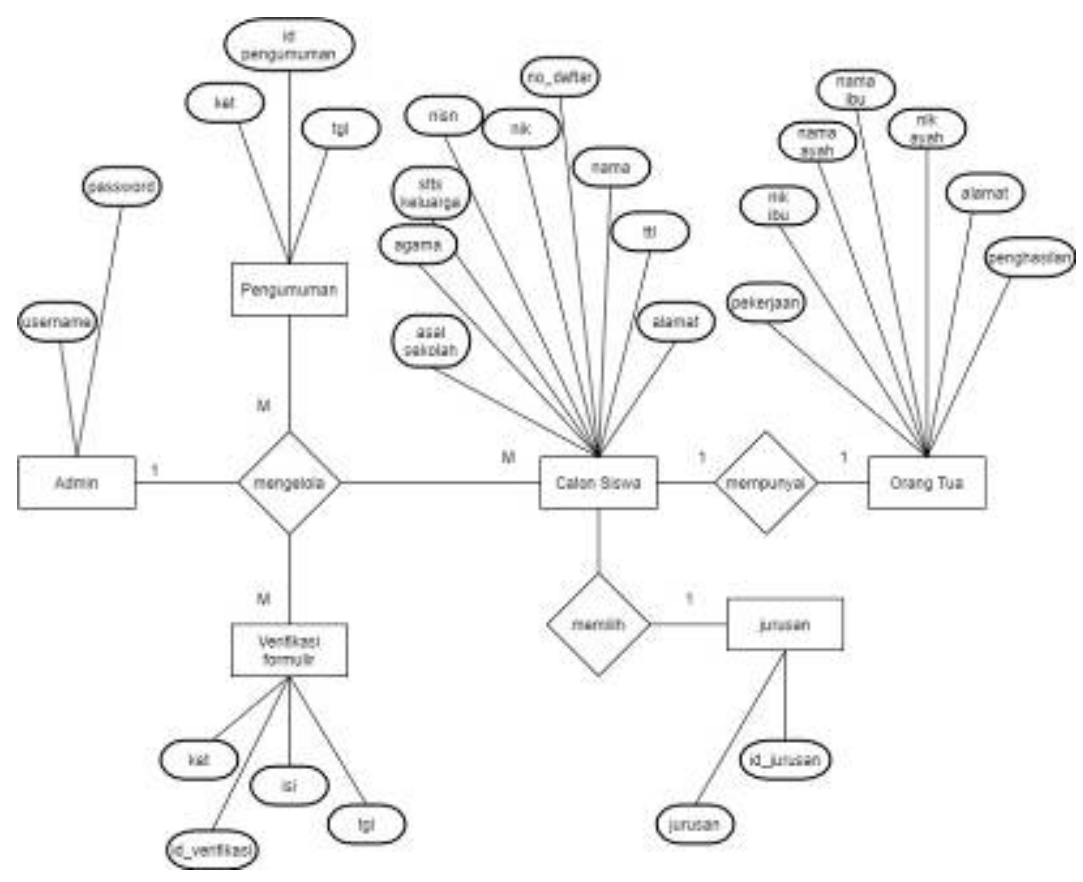

Gambar 3: ERD

Berikut adalah DFD dari Sistem informasi PPDB Online : 


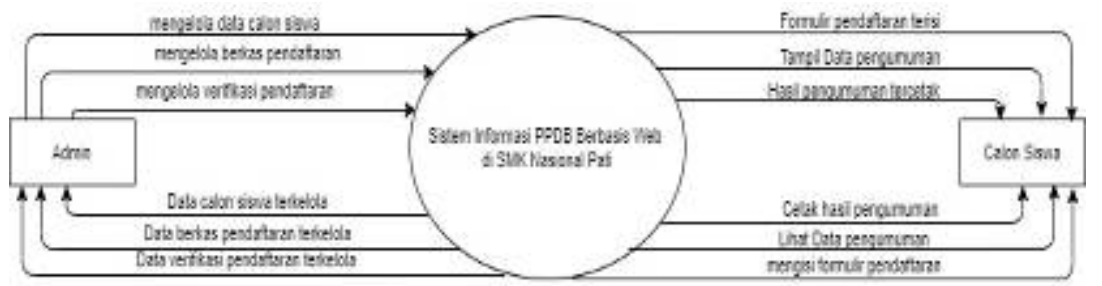

Gambar 4: DFD Level 0

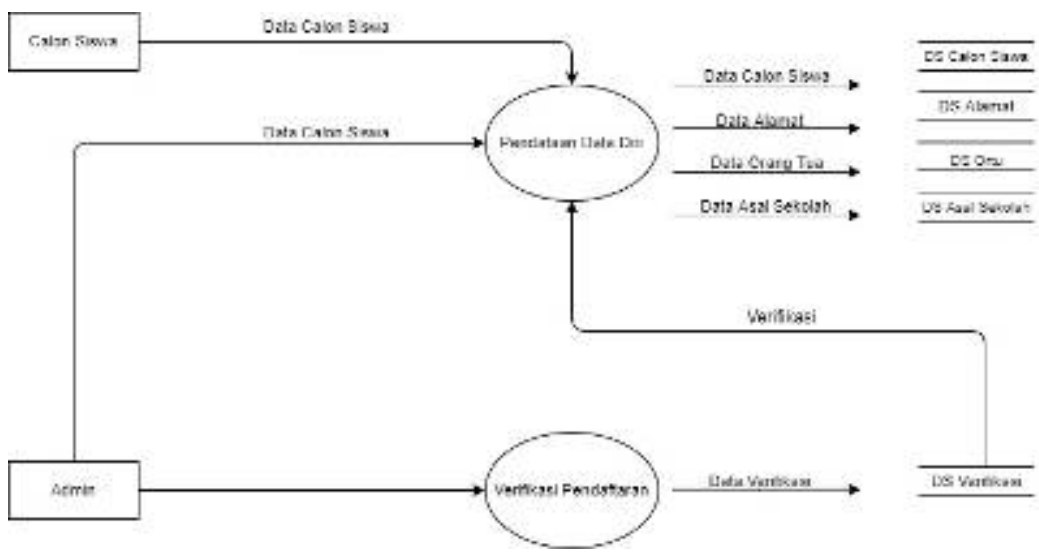

Gambar 5: DFD Level 1

\subsection{Pencapaian Hasil}

Berikut adalah hasil tampilan aplikasi dari Sistem Informasi Penerimaan Peserta Didik Baru Berbasis Online :

1. Halaman Login Admin

Halaman login merupakan halaman untuk admin dengan cara menginputkan username dan password.
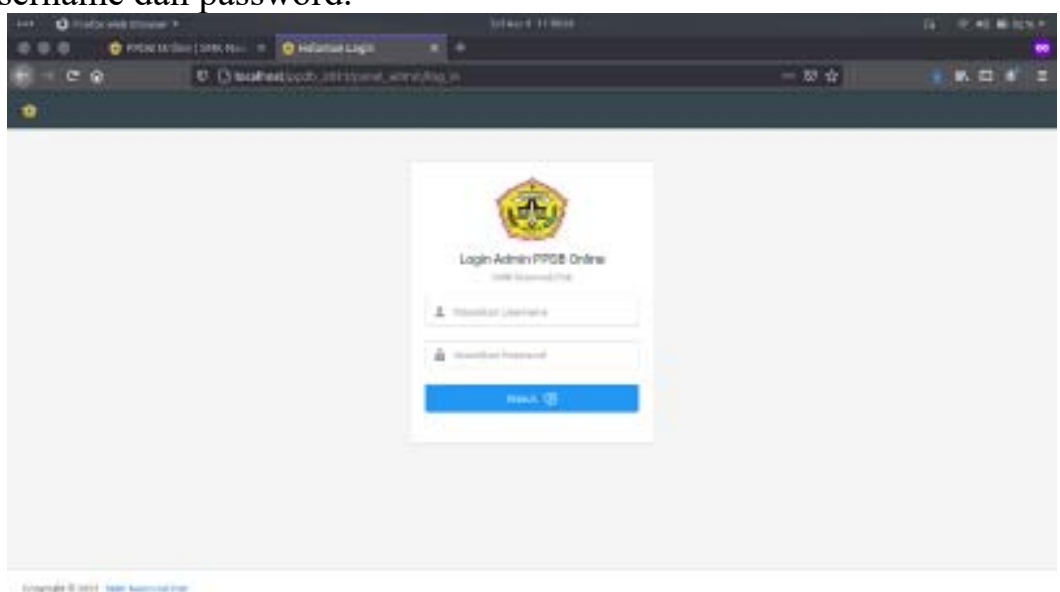

Gambar 6: Tampilan Halaman Admin

2. Halaman Dashboard Admin

Halaman ini berisi tentang data calon siswa yang mendaftar ke SMK Nasional Pati

JURNAL ILMIAH ELEKTRONIKA DAN KOMPUTER Vol. 14, No. 1, Juli $2021: 59$ - 70 


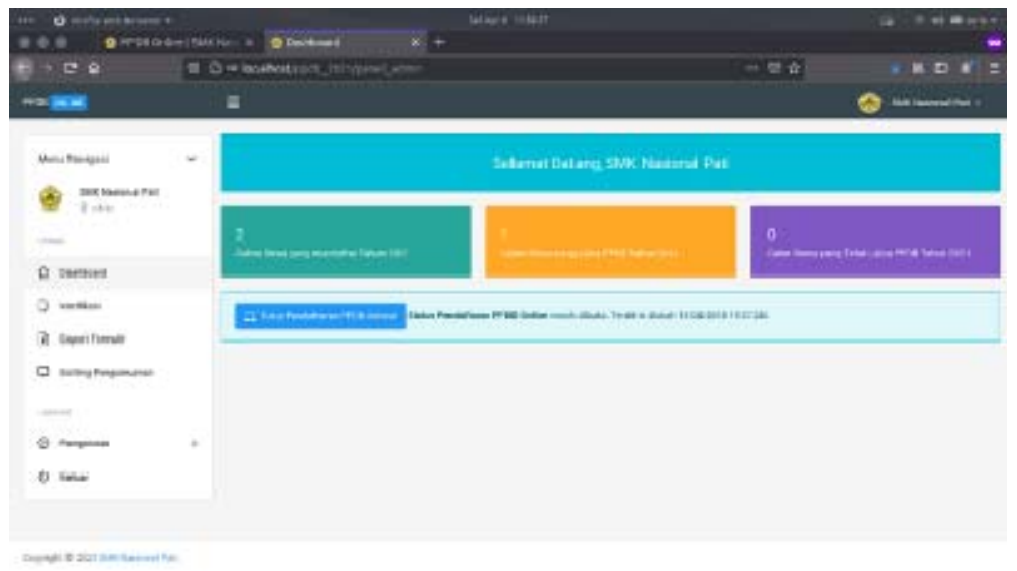

Gambar 7: Tampilan Halaman Dashboard Admin

3. Halaman Verifikasi

Halaman ini berfungsi bagi admin untuk memverifikasi formulir pendaftaran calon peserta didik baru

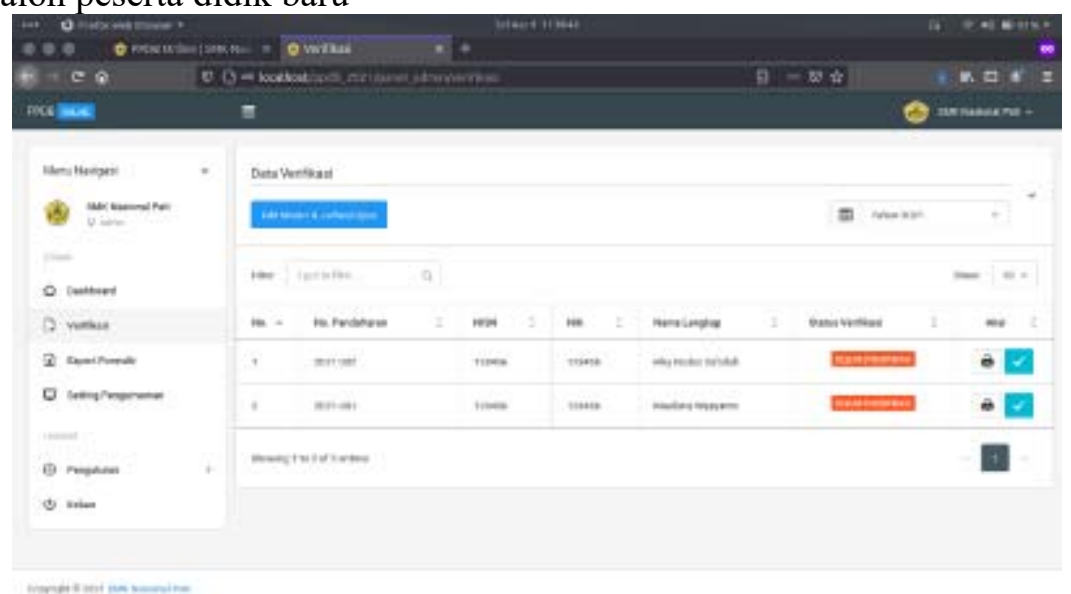

Gambar 8: Tampilan Halaman Verifikasi

4. Halaman Export Formulir

Halaman ini berfungsi bagi admin untuk melakukan export formulir data calon siswa

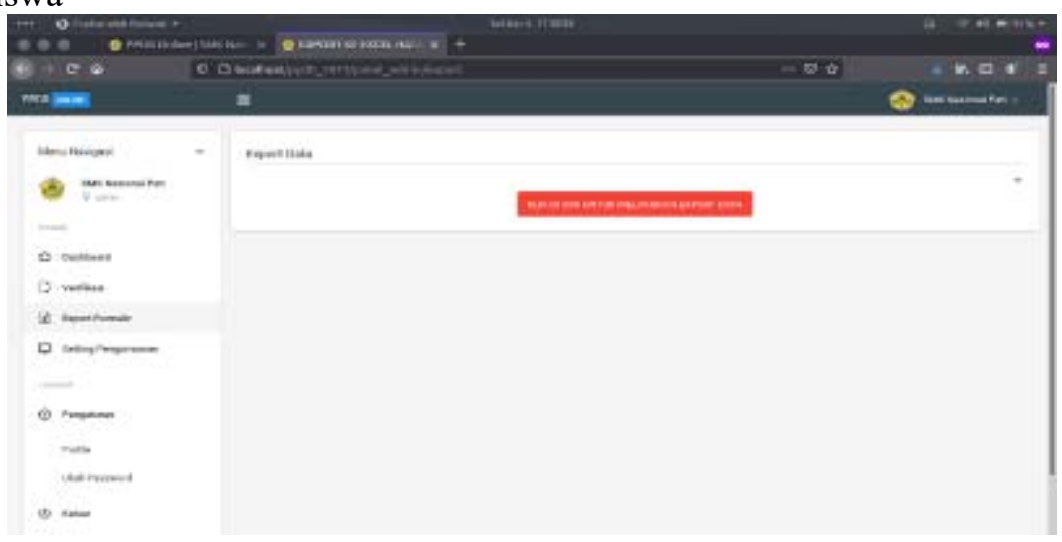

Gambar 9: Tampilan Halaman Export Formulir

5. Halaman setting pengumuman 
Halaman ini berfungsi bagi admin untuk menyetting pengumuman apakah calon siswa tersebut lulus atau tidak.

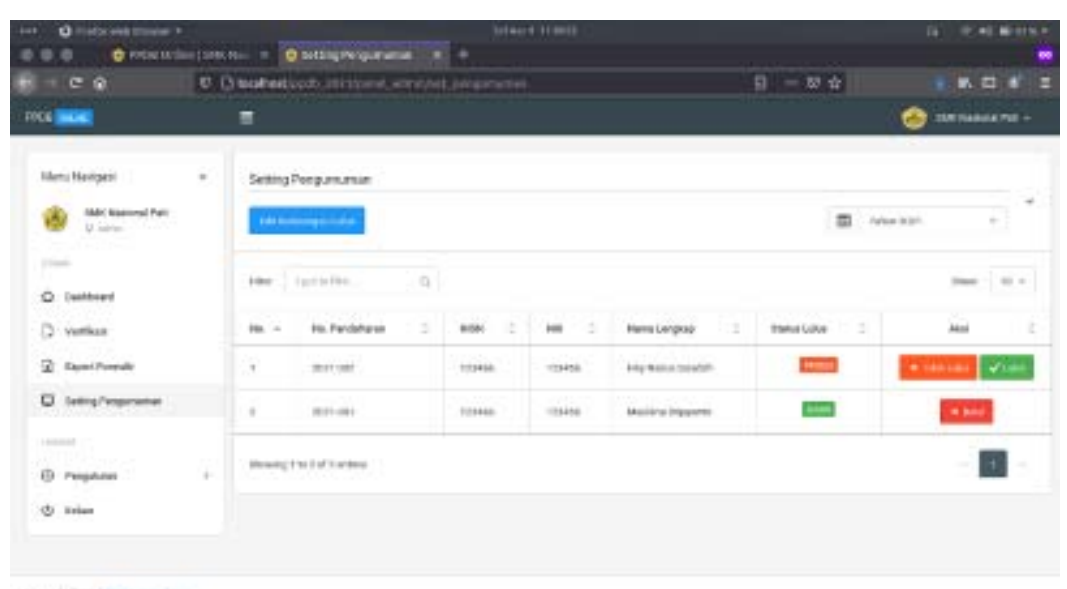

Gambar 10: Tampilan Halaman Setting Pengumuman

6. Halaman Home Pengguna

Halaman ini adalah halaman awal atau homepage dari Sistem Penerimaan Peserta Didik Baru

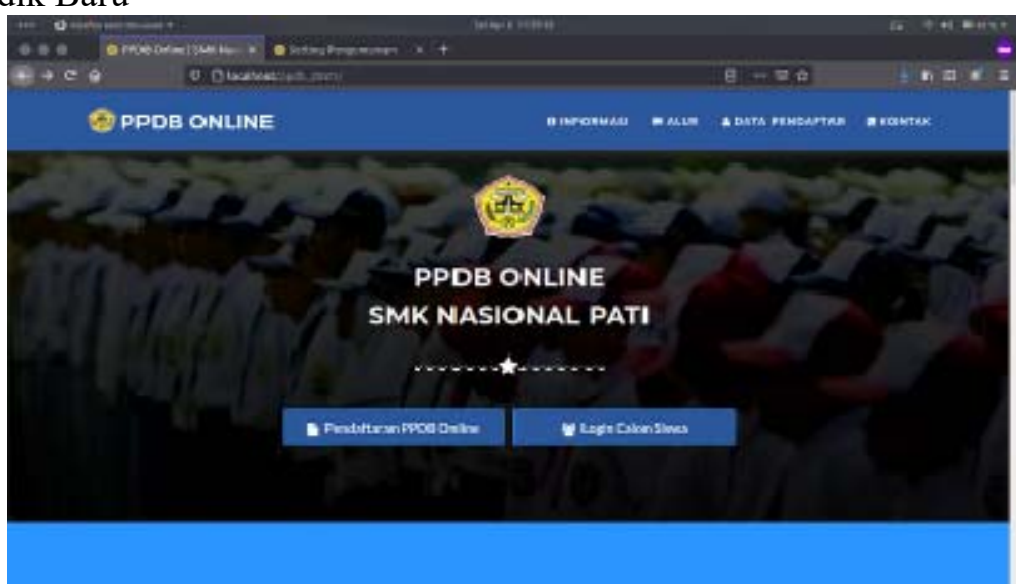

Gambar 11: Tampilan Halaman Home Pengguna

7. Halaman Alur Pendaftaran Peserta Didik Baru

Halaman ini berisi tentang alur bagaimana cara mendaftar di SMK Nasional Pati
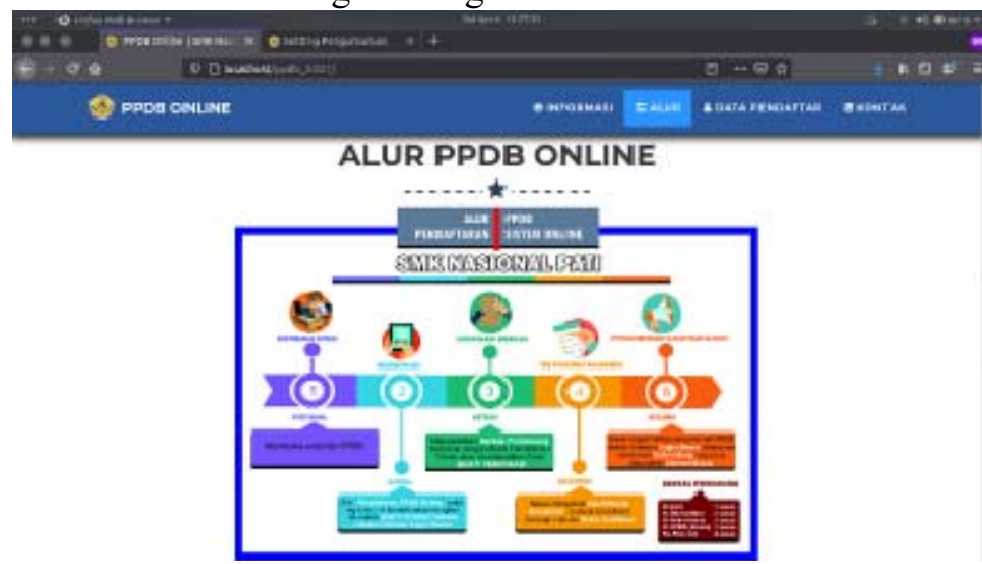

Gambar 12: Halaman Alur Pendaftaran

JURNAL ILMIAH ELEKTRONIKA DAN KOMPUTER Vol. 14, No. 1, Juli $2021: 59$ - 70 
8. Halaman Data Pendaftar

Halaman ini berisi data calon peserta didik baru di SMK Nasional Pati

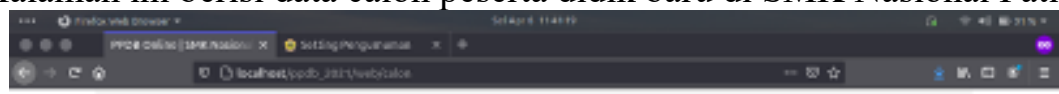

Data Pendaftar PPDB SMK Nasional Pati Tahun Pelajaran 2021-2022

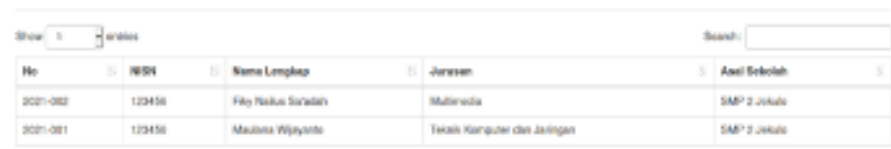

Gambar 13: Tampilan Halaman Data Pendaftar

9. Halaman Kontak

Halaman ini berisi tentang lokasi dan kontak SMK Nasional Pati

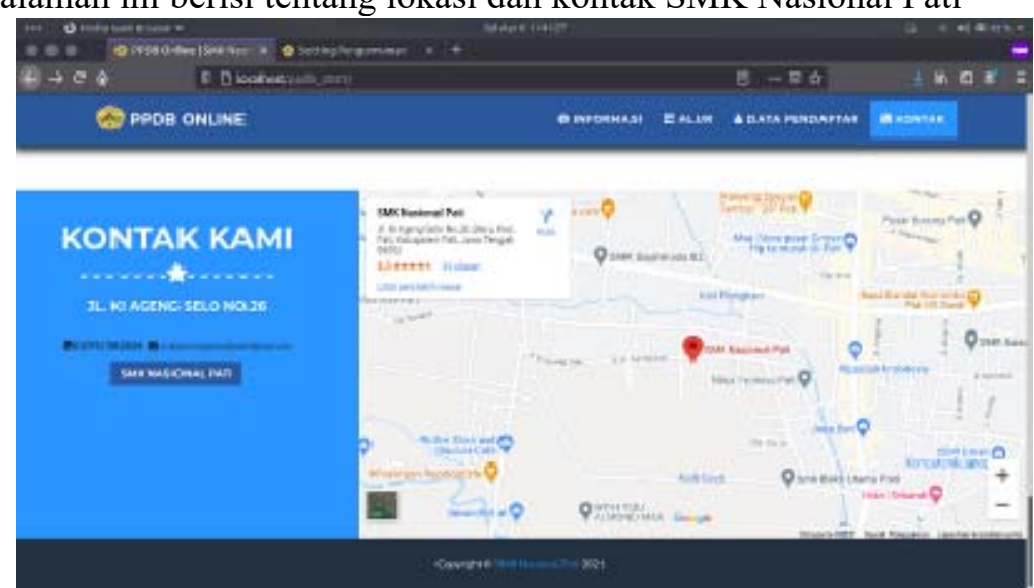

Gambar 14: Tampilan Halaman Kontak

10. Halaman Form Pendaftar

Halaman ini berisi tentang formulir pendaftaran bagi calon siswa

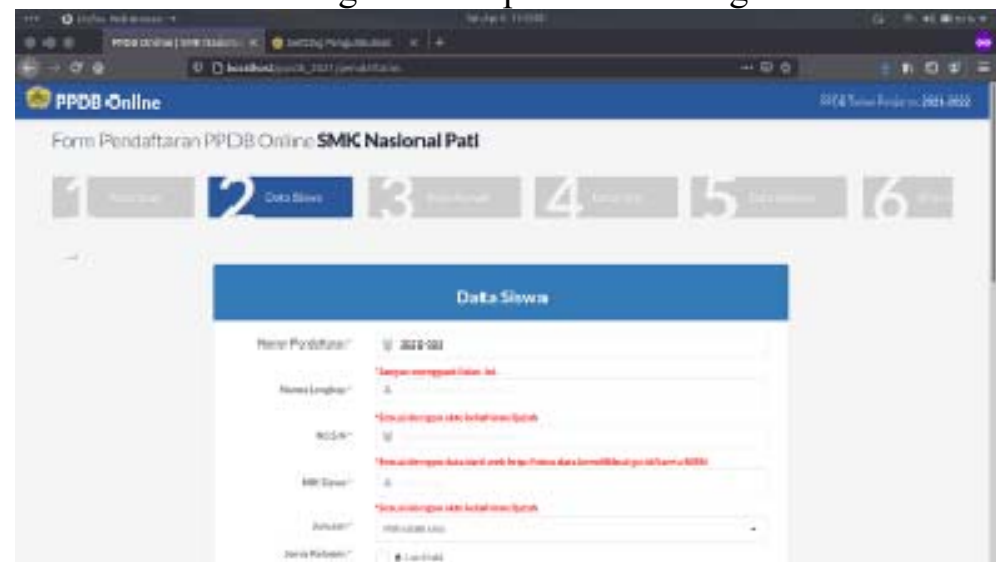

Gambar 15: Tampilan Halaman Form Pendaftaran 
11. Tampilan Halaman Login Pengguna / Calon Peserta Didik

Halaman ini bagi calon siswa ketika sudah mendaftar dan mempunyai username serta password berupa No. Pendaftaran dan NISN untuk login

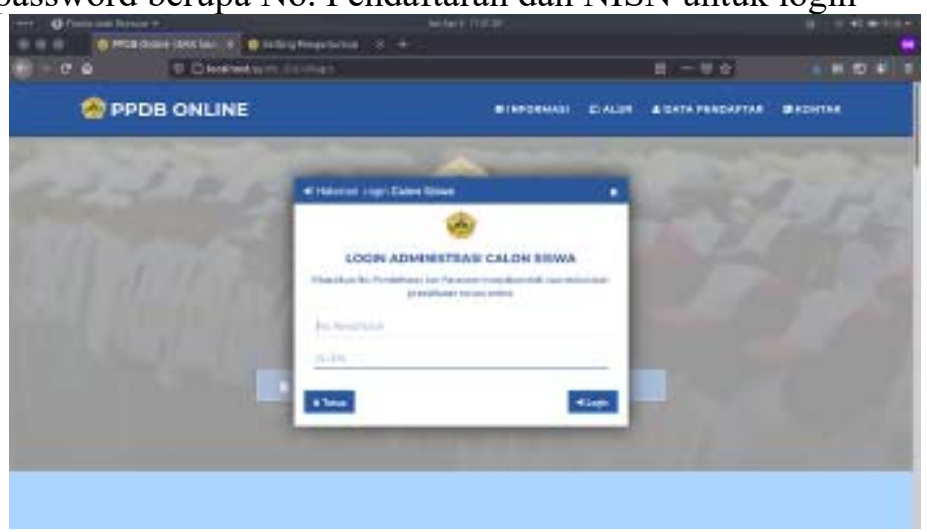

Gambar 16: Tampilan Halaman Login Pengguna

12. Halaman Dashboard

Halaman ini mencakup biodata pendaftaran dan cetak bukti pendaftaran serta pengumuman hasil kelulusan

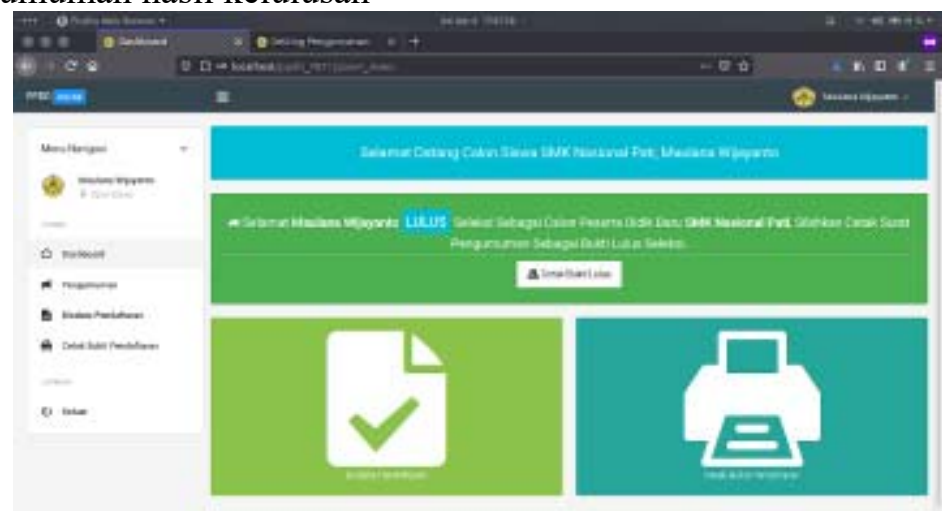

Gambar17: Tampilan Halaman Dashboard Pengguna

13. Halaman Pengumuman

Halaman ini berisi tentang pengumuman bagi calon siswa apakah diterima sebagai siswa di SMK Nasional Pati atau tidak

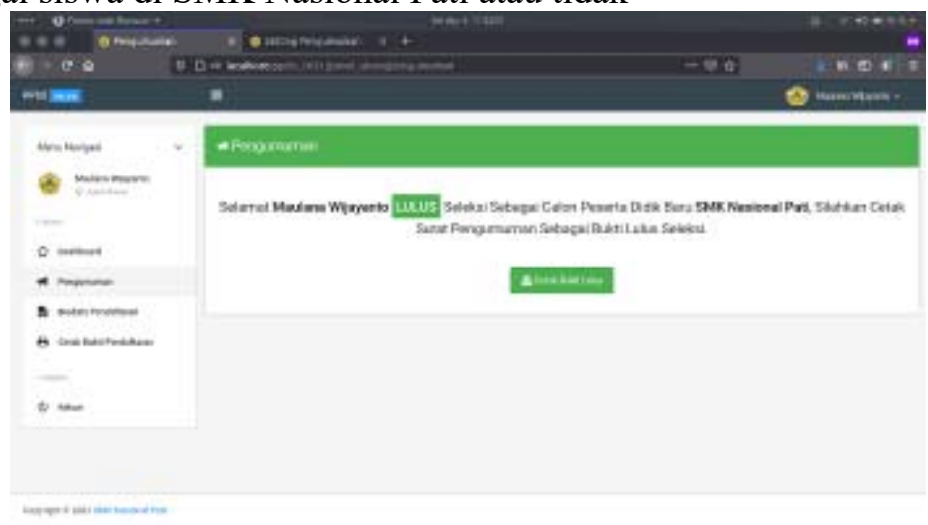

Gambar 18: Tampilan Halaman Pengumuman

JURNAL ILMIAH ELEKTRONIKA DAN KOMPUTER Vol. 14, No. 1, Juli $2021: 59$ - 70 
14. Halaman Biodata Pendaftar

Halaman ini berisi tentang biodata calon siswa

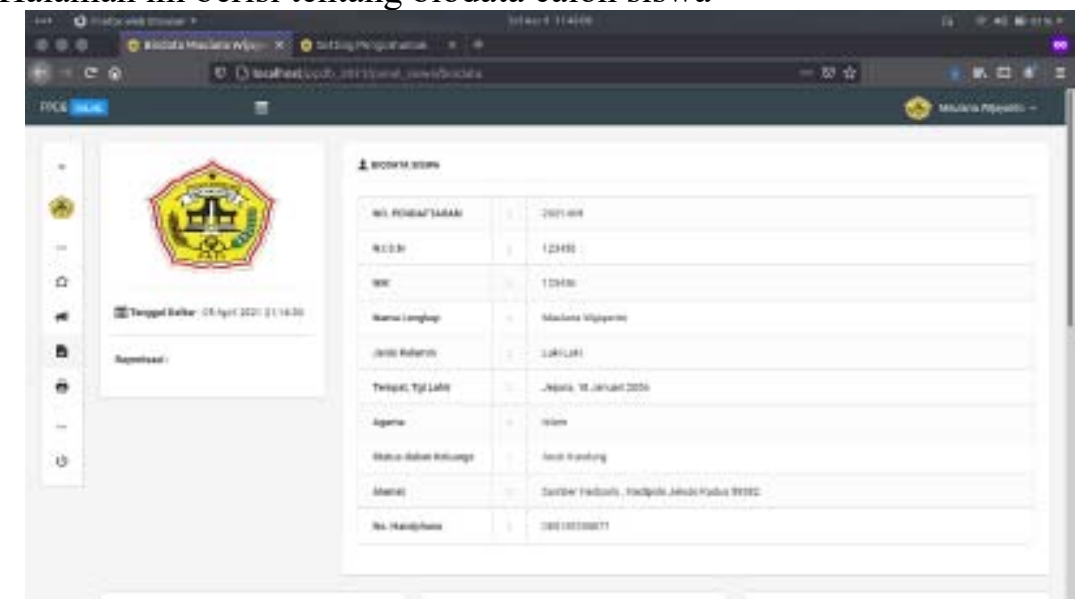

Gambar 19: Tampilan Halaman Biodata Pendaftar

15. Halaman Cetak Bukti Pendaftaran

Halaman ini berisi tentang cetak bukti pendaftaran

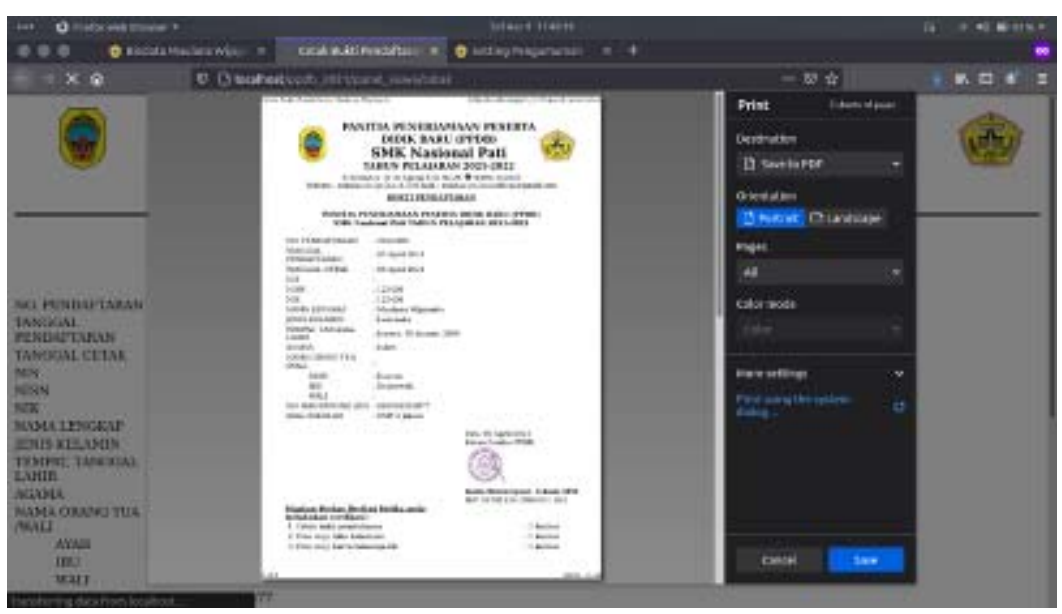

Gambar 20: Tampilan Halaman Cetak Pendaftaran

\section{Kesimpulan dan Saran}

\subsection{Kesimpulan}

Setelah melalui proses pembangunan perangkat lunak Sistem Informasi Penerimaan Peserta Didik Baru Berbasis Online, kesimpulan yang didapat sebagai berikut :

1. Sistem aplikasi Penerimaan Peserta Didik Baru Berbasis Online dapat memudahkan pihak SMK Nasional Pati dalam pengelolaan dan pengolahan data calon peserta didik baru.

2. Sistem aplikasi Penerimaan Peserta Didik Baru Berbasis Online dapat menangani proses penerimaan calon siswa secara lebih efisien dan efektif.

\subsection{Saran}

Setelah proses pembangunan sistem aplikasi penyimpanan dan pendataan surat berbasis web, saran hasil sistem yang didapat adalah sebagai berikut :

1. Pembangunan Sistem aplikasi Penerimaan Peserta Didik Baru Berbasis Online masih perlu diperbaiki dari hasil tampilan sistem agar tampilan menjadi lebih menarik bagi pengguna. 
2. Pembangunan Sistem masih terdapat banyak kekurangan yang masih bisa diperbaiki ataupun dikembangkan karena pembuatan sistem menggunakan bahasa PHP dan MySql sebagai penyimpanan database yang relatif mudah dipelajari

\section{DAFTAR PUSTAKA}

[1]. Hidayat, Taufik. \& Muttaqin, Mahmudin. 2020. Sistem Informasi Penerimaan Peserta Didik Baru Online Berbasis Website di Yayasan Pendidikan Arya Jasa Santika. Tangerang..

[2]. Marysa. Dyna. \& Febriani. Asty. 2014. Sistem Informasi Penerimaan Siswa Baru Sekolah Menengah Pertama Berbasis Web (Studi Kasus Kabupaten Kutai Kertanegara).Kutai Kertanegara.

[3]. PPDB (Def.1) (n.d). Dalam Kamus Besar Bahasa Indonesia. http://etheses.iainkediri.ac.id/ (diakses tanggal 1 April 2021)

[4]. Selvina.Putri. 2011.Pengertian dan Contoh dari DFD dan ERD. http://octaviachaniago.blogspot.com/ (diakses tanggal 2 April 2021)

[5]. SMK (Def.1) (n.d). Dalam Kamus Besar Bahasa Indonesia. https://lektur.id/arti-sekolahmenengah-kejuruan/ (diakses tanggal 5 April 2021) 